\title{
Adsorption and Desorption Characteristics of Cadmium on Different Contaminated Paddy Soil Types: Kinetics, Isotherms, and the Effects of Soil Properties
}

\author{
Weisheng Lu ${ }^{1, \dagger}$, Ying Liu ${ }^{1, \dagger}{ }^{+}$Huike Ye ${ }^{2}$, Dasong Lin ${ }^{2}$, Guijie Li ${ }^{1}$, Yang Zhao ${ }^{1}$, Ting Deng ${ }^{1}$, Huaxing Li ${ }^{1, *}$ \\ and Ruigang Wang ${ }^{2, *}$ \\ 1 College of Natural Resources and Environment, South China Agricultural University, \\ Guangzhou 510640, China; lws2869@scau.edu.cn (W.L.); 15002001585@126.com (Y.L.); \\ guijie2014lele@163.com (G.L.); 18819266120@163.com (Y.Z.); tingdeng0518@163.com (T.D.) \\ 2 Agro-Environmental Protection Institute, Ministry of Agriculture and Rural Affairs, Tianjin 300191, China; \\ yehuike@163.com (H.Y.); lindasong608@126.com (D.L.) \\ * Correspondence: huaxli@scau.edu.cn (H.L.); 3761520835@sina.com (R.W.) \\ + Both authors contribute equally to this work.
}

Citation: Lu, W.; Liu, Y.; Ye, H.; Lin, D.; Li, G.; Zhao, Y.; Deng, T.; Li, H.; Wang, R. Adsorption and Desorption Characteristics of Cadmium on Different Contaminated Paddy Soil Types: Kinetics, Isotherms, and the Effects of Soil Properties. Sustainability 2021, 13, 7052. https:// doi.org/10.3390/su13137052

Academic Editors:

Mohammad Valipour and Marc A. Rosen

Received: 25 April 2021

Accepted: 16 June 2021

Published: 23 June 2021

Publisher's Note: MDPI stays neutral with regard to jurisdictional claims in published maps and institutional affiliations.

Copyright: (c) 2021 by the authors. Licensee MDPI, Basel, Switzerland. This article is an open access article distributed under the terms and conditions of the Creative Commons Attribution (CC BY) license (https:/ / creativecommons.org/licenses/by/ $4.0 /)$.

\begin{abstract}
The adsorption and desorption characteristics of cadmium (Cd) in uncontaminated soils have been investigated in numerous studies. However, similar studies on Cd-polluted soils from different sources, which exhibit complex physicochemical characteristics and internal interactions between $\mathrm{Cd}$ and the soil particles, are scarce. Therefore, in order to elucidate the adsorption and desorption characteristics of $\mathrm{Cd}$ in $\mathrm{Cd}$ polluted soils, six representative Cd-contaminated paddy soil samples were collected from farmlands in the vicinity of a steel plant (Soil 1), a smelter (Soil 2), a thermal power plant (Soil 3), two mining areas (Soil 4, the Dabaoshan mine, Shaoguan; Soil 5, a lead-zinc mine located at Lechang), and a paddy field irrigated with sewage at Zhongshan (Soil 6) in Guangdong Province, China. The analysis of the six soil samples showed that Cd adsorption fitted well to pseudo-second order as well as pseudo-first order kinetics; however, the pseudo-second order equation showed a better fit $\left(R^{2}=0.860-0.962\right)$, while Elovich and intraparticle kinetic models fitted the adsorption kinetics poorly. Further, the adsorption isotherms fitted well to both the Langmuir and Freundlich models, with the Freundlich model showing a better fit $\left(R^{2}=0.96-0.98\right)$. The following order was observed for the $\mathrm{Cd}(\mathrm{II})$ adsorption amount and rate: $\mathrm{S} 5>\mathrm{S} 6>\mathrm{S} 1>\mathrm{S} 3>\mathrm{S} 2>\mathrm{S} 4$; meanwhile, the desorption amount and rate followed the opposite trend. Furthermore, the $\mathrm{pH}$ and soil organic matter were identified as the soil characteristics with the most significant impact on the adsorption and desorption behaviors of $\mathrm{Cd}(\mathrm{II})$ in the Cd-polluted soils.
\end{abstract}

Keywords: cadmium; paddy soil; adsorption and desorption; soil properties

\section{Introduction}

Cadmium is toxic to both plants and humans. Contamination by $\mathrm{Cd}$ is one of the most critical problems in the world that arouses considerable public health concerns [1-3]. Reportedly, anthropogenic activities, such as wastewater irrigation, have resulted in serious Cd contamination of paddy soils in some regions of China [4,5]. Cd in soils can easily be taken up by crops [6-8], and high levels of $\mathrm{Cd}$ in soils can result in $\mathrm{Cd}$ accumulation in crops and eventually in the bodies of humans via the food chain [9-11]. Upon entering the human body, $\mathrm{Cd}$ can be toxic, even at concentrations as low as $0.001 \mathrm{mg} / \mathrm{L}$ [12], Itai-itai disease is caused by the consumption of Cd-contaminated foods. The quantity [13] and concentration $[14,15]$ of $\mathrm{Cd}$ that accumulates in crops is related to the availability of $\mathrm{Cd}$ in soils and can be affected by certain soil properties, including $\mathrm{pH}$ [16], soil organic matter (SOM) content [17,18], iron and manganese oxide contents [19], clay mineral content [20,21], and the composition of solids [22]. 
A series of complex physical interactions and chemical reactions, including adsorptiondesorption, oxidation-reduction, precipitation-dissolution, ion exchange, and chelation reactions, occur when $\mathrm{Cd}$ enters the soil. $\mathrm{Cd}$ adsorption and desorption, which are important processes that occur on the soil surface, affect the concentration of the bioavailable $\mathrm{Cd}$ in soils as well as the $\mathrm{Cd}$ uptake by plants $[23,24]$. However, these processes also depend on the soil charge density and hydrolysis constant of $C d[5,25]$. Previous studies have shown that clay minerals can facilitate $\mathrm{Cd}$ adsorption in loess soil [26]. Tran et al. [27] observed that soil $\mathrm{pH}$ and $\mathrm{Cd}$ concentration are the key factors that affect $\mathrm{Cd}$ adsorption and desorption by goethite at low equilibrium concentrations. However, in a study involving 18 soil types, Wang et al. reported that $\mathrm{pH}$ and $\mathrm{CaCO}_{3}$ are the dominant factors that affect Cd adsorption [28].

As mentioned above, $\mathrm{Cd}$ adsorption and desorption in different kinds of soils might be regulated by different factors. However, in most previous studies on $\mathrm{Cd}$ adsorption and desorption characteristics, uncontaminated soils were generally used; thus, there is limited knowledge regarding $\mathrm{Cd}$ adsorption and desorption behaviors in Cd-contaminated soils. The physicochemical properties of polluted soils are more complex than those of uncontaminated soils [29]; therefore, it is necessary to investigate Cd adsorption and desorption characteristics in polluted soils during the remediation of $\mathrm{Cd}$-polluted soils.

In this study, six representative Cd-polluted type soils were sampled in Guangdong Province. The main objectives of this study were to: (1) investigate the adsorption kinetics and adsorption-desorption isotherms of $\mathrm{Cd}$ and (2) determine the effects of soil physicochemical properties on $\mathrm{Cd}$ adsorption-desorption by conducting batch experiments.

\section{Materials and Methods}

\subsection{Soil Samples}

Six representative Cd-polluted type soil samples were collected from the $0-20 \mathrm{~cm}$ plough layer of paddy fields in six different locations: Soil 1, located at $1 \mathrm{~km}$ from a steel plant at Shaoguan $\left(24^{\circ} 42^{\prime} \mathrm{N}, 113^{\circ} 38^{\prime} \mathrm{E}\right)$; Soil 2, at $2 \mathrm{~km}$ from a smelter at Shaoguan $\left(24^{\circ} 41^{\prime} \mathrm{N}, 113^{\circ} 35^{\prime} \mathrm{E}\right)$; Soil 3 , at $2 \mathrm{~km}$ from a thermal power plant at Shaoguan $\left(24^{\circ} 36^{\prime} \mathrm{N}\right.$, $\left.113^{\circ} 35^{\prime} \mathrm{E}\right)$; Soil 4 , at $16 \mathrm{~km}$ from the Dabaoshan mine at Shaoguan $\left(24^{\circ} 46^{\prime} \mathrm{N}, 113^{\circ} 49^{\prime} \mathrm{E}\right)$; Soil 5, at $1 \mathrm{~km}$ from a lead-zinc mine at Lechang $\left(25^{\circ} 51^{\prime} \mathrm{N}, 113^{\circ} 24^{\prime} \mathrm{E}\right)$; and Soil 6, at a sewage-irrigated paddy field in Zhongshan $\left(22^{\circ} 54^{\prime} \mathrm{N}, 113^{\circ} 41^{\prime} \mathrm{E}\right)$. All six soil samples were paddy soil.

The soil samples were air dried and passed through 20 and 100 mesh.

$\mathrm{pH}$ : The soil $\mathrm{pH}$ value was determined based on a soil-to-water ratio of 1:2.5. The method is described as follows: A $10.00 \mathrm{~g}$ sample of 20 mesh air dried soil was placed into a $50 \mathrm{~mL}$ beaker, and $25 \mathrm{~mL}$ deionized water was added, then mixed for $5 \mathrm{~min}$ before standing for $30 \mathrm{~min}$, and supernatant was measured by phs-3c acidimeter.

SOM: The concentration of SOM was determined by the $\mathrm{K}_{2} \mathrm{Cr}_{2} \mathrm{O}_{7}$ method [30], and the method is described as follows: A $0.20 \mathrm{~g}$ sample of 20 mesh air dried soil was placed into a hard test tube, and $5 \mathrm{~mL}$ potassium chromate and $5 \mathrm{~mL}$ concentrated sulfuric acid was added. This was then digested in an oil bath $\left(170^{\circ} \mathrm{C}-180^{\circ} \mathrm{C}\right)$ for $5 \mathrm{~min}$. The digestion solution was transferred to a $250 \mathrm{~mL}$ triangular flask and titrated with $0.2 \mathrm{~mol} / \mathrm{L} \mathrm{Fe}_{2} \mathrm{SO}_{4}$ with 2-3 drops of o-phenanthroline as an indicator. The content of SOM was calculated by the amount of $\mathrm{Fe}_{2} \mathrm{SO}_{4}$ consumed.

CEC: CECs were determined using the ammonium acetate centrifugal exchange method [31]. A $2.00 \mathrm{~g}$ sample of 20 mesh air dried soil was placed into a $100 \mathrm{~mL}$ centrifuge tube, and $60 \mathrm{~mL} 1 \mathrm{~mol} / \mathrm{L}$ ammonium acetate $(\mathrm{pH}=7.0)$ was added, stirred evenly, then centrifuged for 3-5 min. The treatment was repeated 3-5 times until there was no calcium ion reaction in the leaching solution (K-B indicator was added: blue indicated no calcium ion). Sixty milliliters of $95 \%$ ethanol was added and stirred evenly before being centrifuged for 3-5 min. The treatment was repeated 3-5 times until there was no ammonium ion reaction in the leaching solution (Nessler's reagent was added: no yellow indicated no ammonium ion). The soil samples were washed by deionized water in a Kelvin flask; $0.5 \mathrm{~g}$ 
paraffin and $0.5 \mathrm{~g}$ solid $\mathrm{MgO}$ were addedand the solution distilled. Ammonium ions were absorbed with $25 \mathrm{~mL}$ boric acid indicator solution, and the absorption solution was titrated with hydrochloric acid standard solution.

Clay ratio: Clay ratio analysis was performed by the hydrometer method [31]. A $5.00 \mathrm{~g}$ sample of 20 mesh air dried soil was placed into a $50 \mathrm{~mL}$ centrifuge tube, and $40 \mathrm{~mL}$ $5 \%$ sodium pyrophosphate and $1 \mathrm{~mol} / \mathrm{L} \mathrm{NaOH}$ dilute dispersion was added. The solution was then shaken overnight before $2.5 \mathrm{~mL}$ clay suspension was sucked at a depth of $2.5 \mathrm{~cm}$ from the liquid level with a quantitative pipette, which was then dried and weighted. The percentage of clay content was calculated.

FeDCB and MnDCB: FeDCB and MnDCB were extracted by the sodium dithionatecitrate-bicarbonate (DCB) method [32]. A $1.00 \mathrm{~g}$ sample of 20 mesh air dried soil was placed into a $100 \mathrm{~mL}$ centrifuge tube, before $20 \mathrm{~mL} 0.3 \mathrm{~mol} / \mathrm{L}$ sodium citrate and $2.5 \mathrm{~mL} 1 \mathrm{~mol} / \mathrm{L}$ $\mathrm{NaHCO}_{3}$ were added. The solution was then heated to $80{ }^{\circ} \mathrm{C}$ in a water bath. Then, $0.5 \mathrm{~g}$ sodium bisulfite was added; the mixture was centrifuged after stirring for $15 \mathrm{~min}$. The contents of Fe and $\mathrm{Mn}$ in the supernatant were determined by atomic absorption spectrometry.

FeAAO and MnAAO: FeAAO and MnAAO were extracted by the acidic ammonium oxalate method (AAO) [32]. A $2.00 \mathrm{~g}$ sample of 20 mesh air dried soil was placed into a $250 \mathrm{~mL}$ triangular flask, and $100 \mathrm{~mL} \mathrm{H}_{2} \mathrm{C}_{2} \mathrm{O} 4-\left(\mathrm{NH}_{4}\right)_{2} \mathrm{C}_{2} \mathrm{O}_{4}$ extract was added according to 1:50 soil liquid ratio. The mixture was shaken at $20-25{ }^{\circ} \mathrm{C}$ for $2 \mathrm{~h}$ without light and then transferred to a $100 \mathrm{~mL}$ triangular flask for centrifugation and filtration. The contents of Fe and $\mathrm{Mn}$ in the supernatant were determined by atomic absorption spectrometry.

T-Cd: T-Cd was determined by a flame atomic adsorption spectrophotometer (AAS) after the $\mathrm{HNO}_{3}-\mathrm{HF}-\mathrm{HClO}_{4}$ digestion process [33]. A $0.2000 \mathrm{~g}$ sample of 100 mesh air dried soil was placed into a $50 \mathrm{~mL}$ PTFE crucible, and $5 \mathrm{~mL} \mathrm{HNO}_{3}, 5 \mathrm{~mL} \mathrm{HF}$, and $3 \mathrm{~mL} \mathrm{HClO}_{4}$ were added. The solution was then heated at $180{ }^{\circ} \mathrm{C}$ for $3 \mathrm{~h}$. The mixture was brought to $25 \mathrm{~mL}$, shaken well, and filtered. The contents of $\mathrm{Cd}$ in the filtrate were determined by atomic absorption spectrometry.

The physical and chemical properties of these soil samples are shown in Table 1 . The $\mathrm{pH}$ values of the six samples ranged from 4.85 (S4) to 6.71 (S6). Additionally, the SOM concentrations of the six soil samples followed the order of $44<\mathrm{S} 2<\mathrm{S} 3<\mathrm{S} 1<\mathrm{S} 6<\mathrm{S} 5$; their cation exchange capacities (CECs) followed the order of S1 $<$ S2 $<$ S4 $<$ S3 $<$ S6 $<$ S5, and their total $\mathrm{Cd}$ concentrations (T-Cd) followed the order of $\mathrm{S} 6<\mathrm{S} 4<\mathrm{S} 5<\mathrm{S} 3<\mathrm{S} 1<\mathrm{S} 2$. The values of other parameters, such as free iron oxides $\left(\mathrm{Fe}_{\mathrm{DCB}}\right)$, free manganese oxides $\left(\mathrm{Mn}_{\mathrm{DCB}}\right)$, amorphous iron oxides $\left(\mathrm{Fe}_{\mathrm{AAO}}\right)$, and amorphous manganese oxides $\left(\mathrm{Mn}_{\mathrm{AAO}}\right)$, are shown in Table 1.

Table 1. Physicochemical properties of selected soils.

\begin{tabular}{|c|c|c|c|c|c|c|c|c|c|}
\hline $\begin{array}{c}\text { Soil } \\
\text { Sampling } \\
\text { Sites }\end{array}$ & $\mathrm{pH}$ & $\begin{array}{c}\mathrm{SOM}^{\mathrm{a}} \\
(\mathrm{g} / \mathrm{kg})\end{array}$ & $\begin{array}{c}\text { CEC } \\
\text { (cmol/kg) }\end{array}$ & $\begin{array}{c}\text { Clay } \\
\text { Ratio } \\
<0.002 \\
\text { mm (\%) }\end{array}$ & $\begin{array}{l}\mathrm{Fe}_{\mathrm{DCB}} \\
(\mathrm{g} / \mathrm{kg})\end{array}$ & $\begin{array}{c}\mathrm{Fe}_{\mathrm{AAO}} \\
(\mathrm{g} / \mathrm{kg})\end{array}$ & $\begin{array}{l}\mathrm{Mn}_{\mathrm{DCB}} \\
(\mathrm{mg} / \mathrm{kg})\end{array}$ & $\begin{array}{l}\mathrm{Mn}_{\mathrm{AAO}} \\
(\mathrm{mg} / \mathrm{kg})\end{array}$ & $\begin{array}{c}\text { T-Cd } \\
(\mathrm{mg} / \mathrm{kg})\end{array}$ \\
\hline S1 & 5.53 & 38.06 & 7.47 & 17.88 & 13.84 & 3.69 & 58.68 & 51.48 & 2.61 \\
\hline S2 & 5.13 & 35.17 & 8.06 & 19.01 & 16.54 & 4.19 & 18.31 & 11.14 & 13.08 \\
\hline S3 & 5.28 & 37.82 & 8.89 & 15.45 & 17.91 & 3.89 & 38.25 & 35.11 & 2.35 \\
\hline S4 & 4.85 & 29.05 & 8.66 & 16.33 & 25.18 & 5.63 & 92.24 & 88.30 & 1.12 \\
\hline S5 & 6.71 & 52.12 & 17.53 & 16.39 & 20.80 & 5.35 & 95.29 & 86.60 & 1.99 \\
\hline S6 & 6.28 & 46.67 & 14.76 & 27.05 & 11.70 & 6.33 & 214.89 & 190.00 & 0.60 \\
\hline
\end{tabular}

a $\mathrm{SOM}, \mathrm{CEC}, \mathrm{Fe}_{\mathrm{DCB}}, \mathrm{Mn}_{\mathrm{DCB}}, \mathrm{Fe}_{\mathrm{AAO}}, \mathrm{Mn}_{\mathrm{AAO}}$, and T-Cd soil indicates organic matter, cation exchange capacity, free iron oxides, free manganese oxides, amorphous iron oxides, amorphous manganese oxides, and total cadmium concentration, respectively.

\subsection{Kinetics Adsorption Experiments}

Kinetic adsorption experiments were conducted to determine the $\mathrm{Cd}$ adsorption rate of the six soil samples at a constant temperature of $25{ }^{\circ} \mathrm{C}$. A cadmium stock solution $(30 \mathrm{mg} / \mathrm{L})$ was prepared from $\mathrm{Cd}\left(\mathrm{NO}_{3}\right)_{2}$, and a $\mathrm{NaNO}_{3}$ stock solution $(0.01 \mathrm{~mol} / \mathrm{L})$ served as the background electrolyte. Soil samples $(1 \mathrm{~g})$ were equilibrated with $20 \mathrm{~mL}$ of the 
mixture solutions in a $100 \mathrm{~mL}$ polyethylene centrifuge tube. The mixture was shaken at $200 \mathrm{rpm}$ on a constant-temperature shaker for 5, 10, 20,30, 60, 120, 240, 480, 960, and $1440 \mathrm{~min}$ at $25{ }^{\circ} \mathrm{C}$. Thereafter, the suspension was separated from the solid phase via centrifugation for $10 \mathrm{~min}$ at $5000 \mathrm{rpm}$. The $\mathrm{Cd}$ (II) concentration in the suspension solution was determined using an AAS. The amount of $\mathrm{Cd}(\mathrm{II})$ adsorbed by the soil samples at equilibrium qe $(\mathrm{mg} / \mathrm{kg})$ was calculated according to Equation (1) [34]:

$$
q_{e}=\frac{\mathrm{c}_{0}-\mathrm{c}_{e}}{m} \times V
$$

where $\mathrm{C}_{0}(\mathrm{mg} / \mathrm{L})$ and $\mathrm{C}_{\mathrm{e}}(\mathrm{mg} / \mathrm{L})$ represent the initial and final concentration of $\mathrm{Cd}(\mathrm{II})$, respectively, $V(\mathrm{~mL})$ represents the volume of the solution, and $m(\mathrm{~g})$ represents the mass of the soil sample.

\subsection{Adsorption Kinetics Models}

To investigate the rate law governing Cd(II) adsorption onto the six soil samples, Lagergren pseudo-first order, pseudo-second order, Elovich, and intraparticle diffusion kinetic models were applied to analyze the kinetic data.

The pseudo-first order kinetic equation is generally expressed as [35]:

$$
\log \left(q_{e}-q_{t}\right)=\log q_{e}-\frac{k_{1}}{2.303} t
$$

where $q_{e}(\mathrm{mg} / \mathrm{kg})$ and $q_{t}(\mathrm{mg} / \mathrm{kg})$ represent the amount of $\mathrm{Cd}(\mathrm{II})$ adsorbed per unit adsorbent at equilibrium and at elapsed time, $t(\mathrm{~min})$, respectively, and $k_{1}\left(\mathrm{~min}^{-1}\right)$ represents the pseudo-first order rate constant for the adsorption process.

The pseudo-second order kinetic equation is generally represented as [35]:

$$
\frac{d q_{t}}{d t}=k_{2}\left(q_{e}-q_{t}\right)^{2}
$$

where $k_{2}(\mathrm{~g} / \mathrm{mg} / \mathrm{min})$ represents the pseudo-second order rate constant. This pseudosecond order kinetic equation can be linearized as shown in Equation (4) [35]:

$$
\frac{t}{q_{t}}=\frac{1}{k_{2} q_{e}^{2}}+\frac{1}{q_{e}} t
$$

According to this equation, the ratio time/adsorbed amount is a linear function of time. The slope of the line corresponds to " $q_{e}$," and the lower the amount of $\mathrm{Cd}(\mathrm{II})$ adsorbed, the greater the slope of the curve. The Elovich equation is expressed as [35]:

$$
q_{t}=\beta \ln (\alpha \beta)+\beta \ln t
$$

where $\alpha$ represents the initial sorption rate $(\mathrm{mg} / \mathrm{g} / \mathrm{min})$ and $\beta$ represents the adsorption constant $(\mathrm{g} / \mathrm{mg})$ [36]. The intraparticle diffusion equation is expressed as [35]:

$$
q_{t}=k_{i} t^{0.5}+I
$$

where $k_{i}$ represents the intraparticle diffusion rate constant $\left(\mathrm{mg} / \mathrm{g} / \mathrm{min}^{0.5}\right)$ and $I(\mathrm{mg} / \mathrm{g})$ represents a constant that provides information regarding the thickness of the boundary layer. According to this model, if the plot of qt versus $t^{0.5}$ is a straight line, then the adsorption process is controlled by intraparticle diffusion; however, if the data exhibit multi-linear plots, then two or more steps influence the adsorption process.

\subsection{Isothermal Adsorption-Desorption Experiments}

\subsubsection{Adsorption Isotherm Experiments}

A batch equilibration method was used to investigate the isothermal adsorption of $\mathrm{Cd}(\mathrm{II})$. A mixture containing $1 \mathrm{~g}$ of the soil samples and $20 \mathrm{~mL}$ of the $\mathrm{Cd}\left(\mathrm{NO}_{3}\right)_{2}$ solution 
at concentrations of $0,10,20,40,60$, and $80 \mathrm{mg} / \mathrm{L}$ (with a $0.01 \mathrm{~mol} / \mathrm{L} \mathrm{NaNO}_{3}$ solution as the supporting electrolyte) was introduced into a $100 \mathrm{~mL}$ centrifuge tube. After shaking at $200 \mathrm{rpm}$ for $16 \mathrm{~h}$ at $25^{\circ} \mathrm{C}$, the suspension was centrifuged at $5000 \mathrm{rpm}$ for $10 \mathrm{~min}$, and the $\mathrm{Cd}$ (II) concentration in the solution was determined using an AAS. The total amount of Cd(II) adsorbed at equilibrium, $q_{e}(\mathrm{mg} / \mathrm{kg})$, was calculated using Equation (1).

\subsubsection{Adsorption Isotherm Models}

The data from the isotherm experiments were modeled by fitting them to Langmuir and Freundlich equations. The Langmuir sorption isotherm is usually expressed as [37]:

$$
\frac{C_{e}}{q_{e}}=\frac{C_{e}}{q_{m}}+\frac{1}{K_{L} q_{m}}
$$

where $C_{e}(\mathrm{mg} / \mathrm{L})$ and $q_{e}(\mathrm{mg} / \mathrm{g})$ represent the liquid-phase concentration and solid phase concentration of the adsorbate at equilibrium, respectively, $q_{m}(\mathrm{mg} / \mathrm{g})$ represents the maximum adsorption capacity, and $K_{L}(\mathrm{~L} \mathrm{~m} / \mathrm{g})$ represents the adsorption equilibrium constant.

The Freundlich isotherm is represented as [37]:

$$
\log q_{e}=\log K_{F}+\frac{1}{n} \log C_{e}
$$

where $K_{F}(\mathrm{mg} / \mathrm{g})$ represents the Freundlich constant related to the sorption capacity and $n$ represents the heterogeneity factor.

\subsubsection{Desorption}

The soil residue in the $100 \mathrm{~mL}$ centrifuge tube from the isotherm adsorption experiment was washed with alcohol three times, followed by rinsing with distilled water three times (25 mL each time). Thereafter, $20 \mathrm{~mL}$ of $0.01 \mathrm{~mol} / \mathrm{L} \mathrm{NaNO}_{3}$ was added to the tube, and the mixture was shaken for $16 \mathrm{~h}$ at $25^{\circ} \mathrm{C}$ and centrifuged at $5000 \mathrm{rpm}$ for $10 \mathrm{~min}$ for the determination of the $\mathrm{Cd}(\mathrm{II})$ concentration at equilibrium.

The amount of $\mathrm{Cd}(\mathrm{II})$ desorbed by the soils at equilibrium, $q_{d e}(\mathrm{mg} / \mathrm{kg})$, was calculated according to Equation (9) [37]:

$$
q_{d e}=\frac{C_{f} \times V}{m}
$$

where $C_{f}(\mathrm{mg} / \mathrm{L})$ denotes the final concentration of $\mathrm{Cd}(\mathrm{II})$ at equilibrium, $V(\mathrm{~mL})$ represents the volume of the solution, and $m(\mathrm{~g})$ represents the soil mass.

\subsection{Statistical Analysis}

Excel 2010 and SigmaPlot 10.0 were used to analyze the experimental data. Pearson correlation analysis was used to investigate the relationships between the soil characteristics and sorption parameters. There are several physical and chemical properties that have an effect on the characteristics of $\mathrm{Cd}$ adsorption onto soil particles, and these properties influence and restrict each other. To identify the factors that play the major role in this regard and eliminate secondary factors, a stepwise regression method was adopted. Regression analysis was made by SPSS version 21.0 between the pseudo-second order rate constant $\left(k_{2}\right)$, the maximum adsorption capacity $\left(q_{m}\right)$, the adsorption equilibrium constant $\left(K_{L}\right)$, the Freundlich constant related to the sorption capacity $\left(K_{F}\right)$, the heterogeneity factor $(n)$, and eight different physical and chemical parameters of the soil (including $\mathrm{pH}, \mathrm{SOM}, \mathrm{CEC}$, Clay, $\left.\mathrm{Fe}_{\mathrm{DCB}}, \mathrm{Fe}_{\mathrm{AAO}}, \mathrm{Mn}_{\mathrm{DCB}}, \mathrm{Mn}_{\mathrm{AAO}}\right)$, respectively.

\section{Results and Discussion}

\subsection{Adsorption Kinetics}

Figure 1 shows the results of the $\mathrm{Cd}(\mathrm{II})$ adsorption kinetics experiments with increasing time, from 5 to $1440 \mathrm{~min}$. The shapes of the Cd(II) adsorption simulation curves corresponding to the six soil samples were similar; however, their adsorption capacities 
were significantly different, except for those of S1 and S3. The adsorption amounts of Cd(II) in all the soil samples increased remarkably within the first $30 \mathrm{~min}$; however, after $60 \mathrm{~min}$, the $\mathrm{Cd}(\mathrm{II})$ adsorption amounts corresponding to all six soil samples reached a plateau. Therefore, the Cd(II) adsorption process can be divided into rapid and slow stages, and the turning point appeared at 30-60 $\mathrm{min}$.

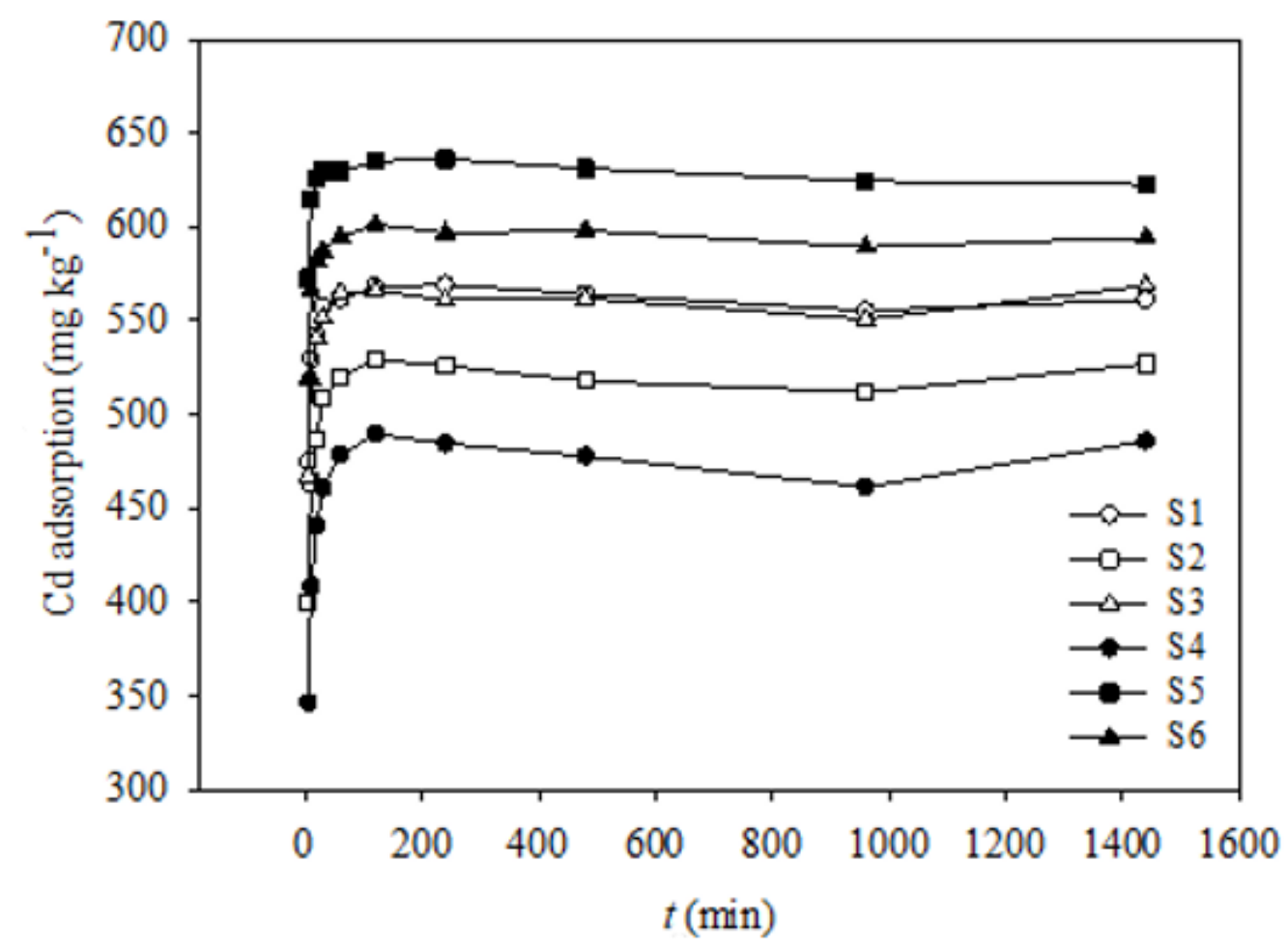

Figure 1. Kinetics of $\mathrm{Cd}$ adsorption onto six soils.

Studies have shown that there are two adsorption types, namely, specific adsorption and non-specific adsorption [38]. Non-specific adsorption refers to the fast adsorption of metal ions onto soil particles via a simple Coulomb force, while specific adsorption refers to a relatively slow adsorption of metal ions onto soil particles owing to the formation of chelates or coprecipitation [39]. In this study, Cd(II) adsorption began with non-specific adsorption, and the fast initial adsorption rate possibly suggests that the binding sites on the external surface of the soil particles were sufficient for $\mathrm{Cd}$ (II) adsorption. As time elapsed, the number of binding sites decreased, such that non-specific adsorption could not take place; thus, specific adsorption became predominant. Similar Cd(II) adsorption patterns have also been reported by Huang et al. [38] and Gao et al. [40].

\subsection{Kinetic Equations for Cd(II) Adsorption}

The parameters corresponding to pseudo-first order, pseudo-second order, Elovich, and intraparticle diffusion kinetic models are shown in Table 2 and Figure 2. The correlation coefficient values $\left(\mathrm{R}^{2}\right)$ indicated that $\mathrm{Cd}(\mathrm{II})$ adsorption onto the six soil samples fitted well to the pseudo-first order and pseudo-second order kinetic equations but fitted poorly to Elovich and intraparticle diffusion kinetics. The pseudo-second order kinetic equation showed the best fit for Cd(II) adsorption, as indicated by the higher $\mathrm{R}^{2}$ values $(0.860-0.962)$. 
Table 2. Parameter Values for the models of Pseudo-first order, Pseudo-second order, Elovich, Intraparticle diffusion, Langmuir, and Freundlich. $\mathrm{R}^{2}$ means the adsorption kinetic or the adsorption isotherm of Cd onto six soils.

\begin{tabular}{|c|c|c|c|c|c|c|c|c|c|c|c|c|}
\hline & \multicolumn{3}{|c|}{$\begin{array}{c}\text { Pseudo-First Order } \\
\ln \left(q_{e}-q_{t}\right)=\ln q_{e}-\frac{k_{1}}{2.303} t\end{array}$} & \multicolumn{3}{|c|}{$\begin{array}{l}\text { Pseudo-Second Order } \\
\frac{d q_{t}}{d t}=k_{2}\left(q_{e}-q_{t}\right)^{2}\end{array}$} & \multicolumn{3}{|c|}{$\begin{array}{l}\text { Elovich } \\
q_{t}=\beta \ln (\alpha \beta)+\beta \ln t\end{array}$} & \multicolumn{3}{|c|}{$\begin{array}{l}\text { Intraparticle Diffusion } \\
\qquad q_{t}=q_{e}+k_{i} t^{0.5}\end{array}$} \\
\hline & $q_{e}$ & $k_{1}$ & $R^{2}$ & $q_{\mathrm{e}}$ & $k_{2}$ & $R^{2}$ & $\alpha$ & $\beta$ & $R^{2}$ & $q_{e}$ & $k_{i}$ & $R^{2}$ \\
\hline S1 & 558.6 & 0.37 & 0.879 & 567.2 & 1.98 & 0.948 & 501.5 & 10.40 & 0.500 & 533.3 & 1.07 & 0.217 \\
\hline S2 & 514.8 & 0.28 & 0.867 & 526.9 & 1.26 & 0.962 & 427.5 & 15.88 & 0.579 & 474.4 & 1.75 & 0.289 \\
\hline S3 & 556.5 & 0.35 & 0.858 & 566.1 & 1.76 & 0.956 & 491.5 & 11.90 & 0.543 & 526.7 & 1.31 & 0.268 \\
\hline S4 & 471.1 & 0.24 & 0.850 & 484.7 & 1.07 & 0.955 & 373.7 & 17.69 & 0.580 & 426.1 & 1.93 & 0.285 \\
\hline S5 & 628.4 & 0.48 & 0.850 & 633.5 & 3.46 & 0.860 & 598.0 & 5.37 & 0.319 & 615.8 & 0.45 & 0.091 \\
\hline \multirow[t]{3}{*}{ S6 } & 591.6 & 0.41 & 0.892 & 599.1 & 2.36 & 0.952 & 542.9 & 8.90 & 0.494 & 570.0 & 0.92 & 0.217 \\
\hline & \multicolumn{6}{|c|}{$\begin{array}{c}\text { Langmuir } \\
\frac{C_{e}}{q_{e}}=\frac{C_{e}}{q_{\max }}+\frac{1}{K_{L} q_{\max }}\end{array}$} & \multicolumn{6}{|c|}{$\begin{array}{c}\text { Freundlich } \\
\log q_{e}=\log K_{F}+\frac{1}{n} \log C_{e}\end{array}$} \\
\hline & \multicolumn{2}{|c|}{$q_{\max }$} & \multicolumn{2}{|c|}{$K_{L}$} & \multicolumn{2}{|c|}{$R^{2}$} & \multicolumn{2}{|c|}{$K_{F}$} & \multicolumn{2}{|c|}{$n$} & \multicolumn{2}{|c|}{$R^{2}$} \\
\hline S1 & \multicolumn{2}{|c|}{1454.0} & \multicolumn{2}{|c|}{0.28} & \multicolumn{2}{|c|}{0.96} & \multicolumn{2}{|c|}{344.4} & \multicolumn{2}{|c|}{2.10} & \multicolumn{2}{|c|}{0.98} \\
\hline S2 & \multicolumn{2}{|c|}{1428.5} & \multicolumn{2}{|c|}{0.12} & \multicolumn{2}{|c|}{0.98} & \multicolumn{2}{|c|}{196.2} & \multicolumn{2}{|c|}{1.78} & \multicolumn{2}{|c|}{0.98} \\
\hline S3 & \multicolumn{2}{|c|}{1436.7} & \multicolumn{2}{|c|}{0.24} & \multicolumn{2}{|c|}{0.96} & \multicolumn{2}{|c|}{316.1} & \multicolumn{2}{|c|}{2.05} & \multicolumn{2}{|c|}{0.98} \\
\hline S4 & \multicolumn{2}{|c|}{1204.9} & \multicolumn{2}{|c|}{0.11} & \multicolumn{2}{|c|}{0.96} & \multicolumn{2}{|c|}{168.4} & & & & \\
\hline S5 & & & & & & & & & & & & \\
\hline S6 & & & & & & & & & & & & \\
\hline
\end{tabular}

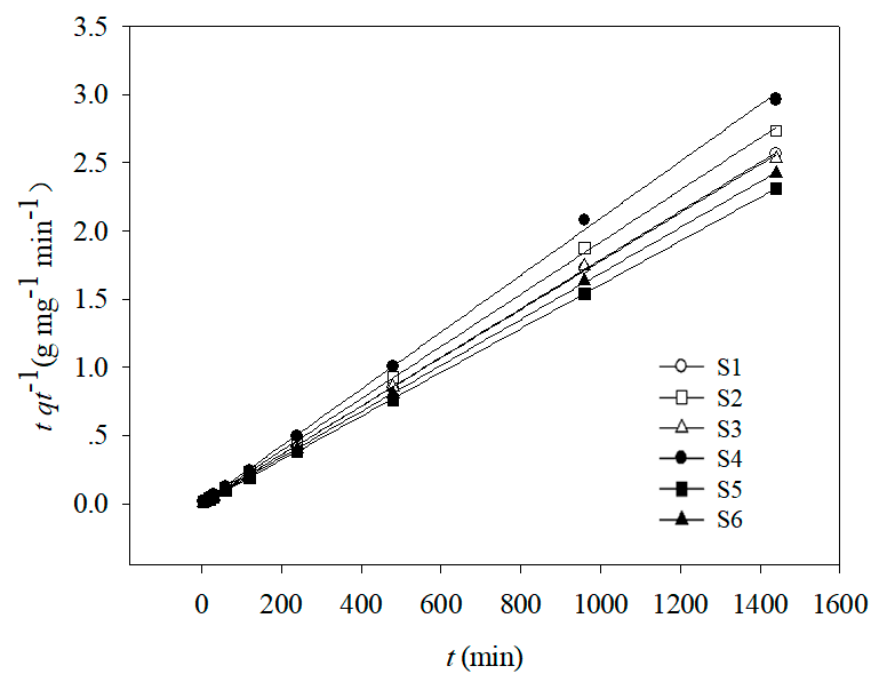

Figure 2. Pseudo-second-order adsorption kinetics of Cd(II) onto six soils.

The Lagergren pseudo-second order kinetics equation can be used to describe the adsorption rates of elements in liquid-phase systems, and it has been one of the most commonly used equations for describing adsorption [41]. In this study, the good fit of the adsorption data with this pseudo-second order model suggests that the rate controlling step was chemical sorption, which is consistent with the results reported by Zhu et al. [42].

Both experimental studies and theoretical investigations have indicated that the " $k_{2}$ " value usually depends on soil properties. Stepwise multiple regression analysis was used to evaluate the effect of soil properties on the $\mathrm{Cd}(\mathrm{II})$ adsorption rate. Equation (10) indicated that the soil property with the most significant effect on " $k_{2}$ " was $\mathrm{pH}$. This is consistent with the results of several previous studies [38,43-45]. The maximum " $k_{2}$ " value (3.46) corresponded to soil sample S5, which had the highest $\mathrm{pH}$ value (Table 2), followed by $\mathrm{S} 6>\mathrm{S} 1>\mathrm{S} 3>\mathrm{S} 2>\mathrm{S} 4$, with decreasing $\mathrm{pH}$ values.

Possibly, this phenomenon, which has been discussed in other similar studies [38,43], occurred because when the $\mathrm{pH}$ is lowered, the competition between heavy metal ions and the abundance of $\mathrm{H}^{+}$for available binding sites increases, thereby limiting the adsorption 
of the heavy metal ions onto soil particles. Conversely, when the $\mathrm{pH}$ value increases, the competition becomes weaker; thus, more heavy metal ions are adsorbed. Therefore, low $\mathrm{pH}$ conditions favored $\mathrm{Cd}$ desorption from the soil particles into solution, increasing the possibly of their migration into the environment. Additionally, the $\mathrm{pH}$ also showed a significant effect on CEC, which is another major soil property that had an effect on cadmium adsorption; therefore, increasing the soil $\mathrm{pH}$ may enhance the $\mathrm{Cd}(\mathrm{II})$ adsorption rate owing to an increase in CEC [46]:

$$
k_{2}=1.16 \mathrm{pH}-4.55 \quad \mathrm{R}^{2}=0.91 \quad p \leq 0.05 .
$$

\subsection{Adsorption Isotherms}

The adsorption isotherms for the adsorption of cadmium onto the six soil samples are shown in Figure 3. From the isotherm curves, the cadmium adsorption capacity of each soil sample increased as the equilibrium solute concentration increased. At low equilibrium concentrations, the $\mathrm{Cd}$ adsorption amount increased almost linearly, and, at high equilibrium concentrations, it tended to flatten; however, there were differences among the six soil samples. Sample S5 showed the maximum Cd adsorption amount, followed by $\mathrm{S} 6>\mathrm{S} 1>\mathrm{S} 3>\mathrm{S} 2>\mathrm{S} 4$.

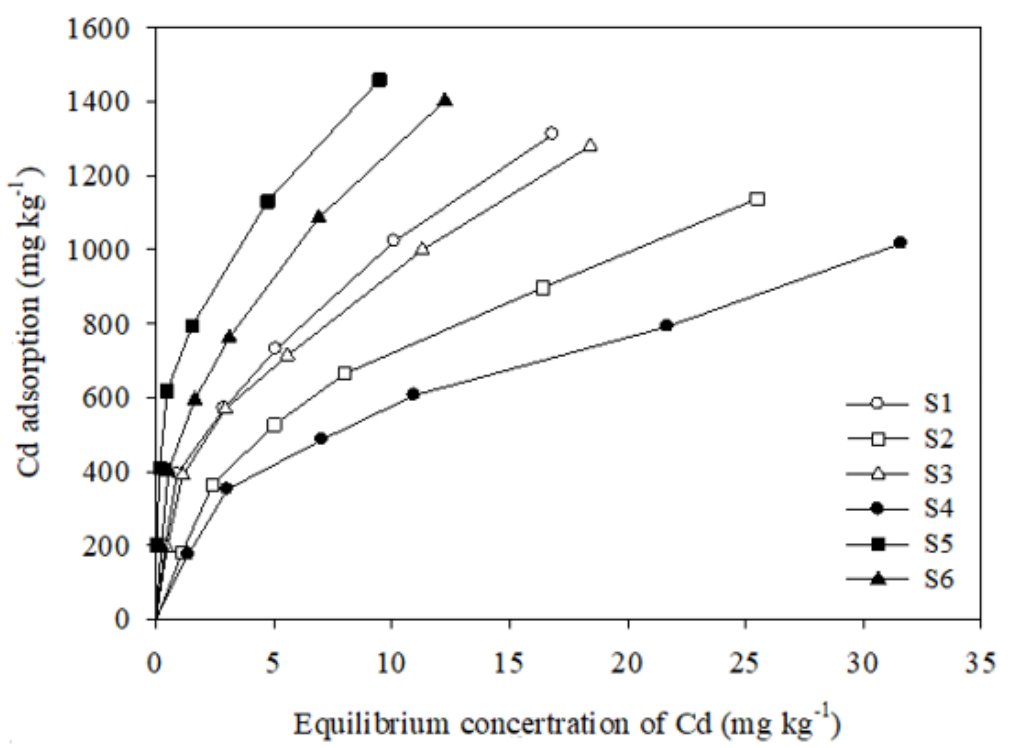

Figure 3. Isotherms of $\mathrm{Cd}$ adsorption onto six soils.

\subsection{Isotherm Equations for Cd(II) Adsorption}

Langmuir and Freundlich models were used to fit the data corresponding to the isotherm adsorption of $\mathrm{Cd}$ onto the six soil samples. The squares of the determination coefficients $\left(R^{2}\right)$ are shown in Table 2.

The Langmuir isotherm is suitable for the description of monolayer adsorption on homogenous surfaces without any interaction between the absorbent and adsorbate and has been extensively employed to describe the adsorption behavior of phosphate ions onto soil particles. It has been widely applied in studying the progression of adsorption and precipitation $[26,39,47]$. The maximum adsorption capacity (qm) and the Langmuir adsorption constant $(\mathrm{KL})$, which are related to bonding strength, were determined, and the Langmuir isotherm was well fitted with the experimental data $\left(R^{2}=0.96-0.98\right)$, as shown in Table 2. The adsorption bonding strength and the amount of $\mathrm{Cd}$ adsorbed onto the six soil samples were in the ranges $0.11-1.20 \mathrm{~L} / \mathrm{kg}$ and $1204.9-1668.0 \mathrm{mg} / \mathrm{kg}$, respectively. The maximum adsorption amount corresponded to sample S5, which showed the strongest Cd(II) adsorption affinity. 
A stepwise multiple regression analysis among $q_{m}, \mathrm{KL}$, and the soil properties indicated that SOM was the main soil property controlling the $\mathrm{Cd}(\mathrm{II})$ maximum adsorption capacity, while $\mathrm{pH}$ was the main factor controlling adsorption bonding strength (Equations (11) and (12)).

A study conducted by Ahmed et al. [39] showed that, among the various soil constituents, organic matter has the largest adsorption capacity, which is an important factor that affects the soil adsorption capacity [38]. This is because SOM provides available surface sites for metal adsorption and facilitates the formation of metal-ligand complexes on the surface of soil particles. Further, they can also inhibit metal adsorption via the formation of non-extractable complexes with metal ions $[5,39]$ :

$$
\begin{array}{ccc}
q_{m}=17.67 \mathrm{SOM}+751.8 & \mathrm{R}^{2}=0.92 & p \leq 0.05, \\
K_{\mathrm{L}}=0.51 \mathrm{pH}-2.48 & \mathrm{R}^{2}=0.89 & p \leq 0.05 .
\end{array}
$$

The Freundlich isotherm is an empirical equation that showed better adaptability. It has mainly been applied to heterogeneous surfaces with a non-uniform distribution of adsorption heat over the surface of the adsorbent because it assumes that the different adsorptive sites on the absorbent have different energies [48,49]. Cd adsorption isotherm data from the six soil samples fitted the Freundlich model better than the Langmuir model, as indicated by the higher $\mathrm{R}^{2}$ values $(0.98-0.99)$. The Freundlich adsorption isotherm constant, which is indicative of the adsorption capacity $\left(K_{F}\right)$, as well as the degree of nonlinearity between the adsorption and solution concentration $(n)$ are shown in Table 2.

The relationships between $\mathrm{K}_{\mathrm{F}}, \mathrm{n}$, and soil properties were described using a stepwise multiple regression analysis (Equations (13) and (14)), which indicated that the $\mathrm{pH}$ was the dominant soil property affecting $\mathrm{KF}$ and $\mathrm{n}$, implying that the $\mathrm{Cd}$ adsorption capacity of the soil samples increased with a decrease in $\mathrm{pH}$ :

$$
\begin{array}{crr}
K_{F}=260.21 \mathrm{pH}-1102.82 & \mathrm{R}^{2}=0.93 & p \leq 0.05, \\
n=0.49 \mathrm{pH}-0.61 & \mathrm{R}^{2}=0.95 & p \leq 0.05 .
\end{array}
$$

\subsection{Desorption Isotherms}

The results of $\mathrm{Cd}(\mathrm{II})$ desorption from the six soil samples (Figure 4) showed that $\mathrm{Cd}$ (II) desorption from the soil samples increased significantly as the Cd(II) adsorption amount increased. Thus, $\mathrm{Cd}$ desorption was related to the adsorption process. Specific adsorption decreased as the adsorption amount as well as the exchangeable adsorption amount increased. Thus, an increasing number of ions adsorbed onto low potential energy sites and easily desorbed at high adsorption amounts, leading to an increase in the amount of the adsorbed $\mathrm{Cd}$ (II) that desorbed into solution. The $\mathrm{Cd}$ (II) desorption amounts were significantly less than the adsorption amounts. This finding is consistent with previous reports $[5,27,50,51]$ and indicates that $\mathrm{Cd}$ (II) desorption from the six soil samples was incomplete and only partially reversible.

Considering the adsorption isotherms of the six soil samples, sample S4 showed the maximum Cd desorption amount, followed by S2, S3, S1, and S6, in order, with S5 showing the lowest desorption amount. Adsorbed ions that can be desorbed by unbuffered salts are ions that are absorbed electrostatically $[5,52,53]$. Therefore, the $\mathrm{Cd}$ (II) desorbed by $\mathrm{NaNO}_{3}$ was previously adsorbed via electrostatic attraction, so the desorption of $\mathrm{Cd}(\mathrm{II})$ represents the relative contribution of electrostatic adsorption to the total adsorption of $\mathrm{Cd}$ (II). The results of $\mathrm{Cd}$ (II) desorption corresponding to the six soil samples suggest that the $\mathrm{Cd}(\mathrm{II})$ adsorbed on sample $\mathrm{S} 4$ was characterized by a relatively higher mobility, which, due to $\mathrm{Cd}(\mathrm{II})$ adsorption via electrostatic attraction, was easily desorbed from the soil particles into solution. The increase in the $\mathrm{Cd}$ (II) desorption amount corresponding to the six soil samples may be attributed to the decrease in SOM content and $\mathrm{pH}$. Specifically, SOM can form stable complexes with $\mathrm{Cd}(\mathrm{II})$ that cannot be desorbed by $\mathrm{NaNO}_{3}[5,54]$. 


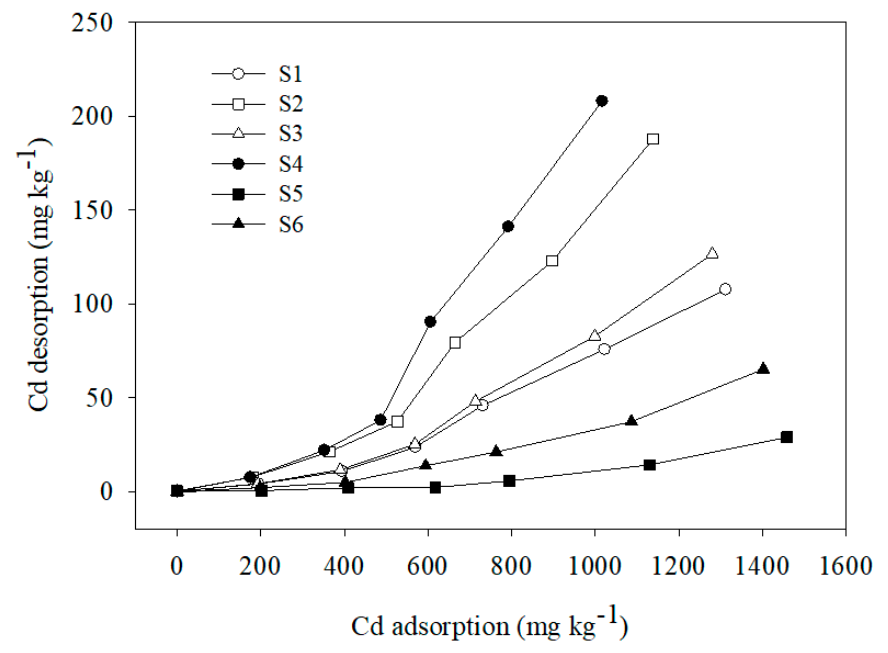

Figure 4. Desorption curve of Cd onto six soils.

\section{Conclusions}

The results of $\mathrm{Cd}$ (II) adsorption kinetics experiments showed that $\mathrm{Cd}(\mathrm{II})$ adsorption was characterized by a rapid initial stage, which lasted for approximately 30-60 $\mathrm{min}$; this was followed by slow desorption, indicating that the process involved two different mechanisms. Further, the kinetics of $\mathrm{Cd}(\mathrm{II})$ adsorption onto the six soil samples were adequately described by the pseudo-second order equation, and data from the isotherm adsorption experiments fitted well with both the Langmuir and Freundlich models; however, the Freundlich model showed a better fit. Furthermore, the highest adsorption amount and adsorption rate corresponded to sample S5, while the lowest values corresponded to sample S4. The soil properties with the most significant effect on the adsorption rate and the maximum adsorption amount were the $\mathrm{pH}$ and soil organic carbon content, respectively. Considering the adsorption isotherms, samples S4 and S5 showed the highest and lowest $\mathrm{Cd}$ (II) desorption amounts, respectively, and this could be attributed to the effects of SOM and $\mathrm{pH}$.

Author Contributions: W.L., Y.L., R.W. contributed to the conception of the study; W.L., Y.L., G.L. performed the experiment; W.L., H.L., H.Y. contributed significantly to analysis and manuscript preparation; R.W., D.L., H.L. performed the data analyses and wrote the manuscript; T.D., Y.Z., R.W. helped perform the analysis with constructive discussions. All authors have read and agreed to the published version of the manuscript.

Funding: This research was funded by the National Science Foundation of China $(41271266,41877403)$. The views expressed herein are those of the authors and do not represent the views of the funding agencies or any of its subagencies.

Institutional Review Board Statement: Not applicable.

Informed Consent Statement: Not applicable.

Conflicts of Interest: The authors declare no conflict of interest.

\section{References}

1. Unuabonah, E.; Adebowale, K.; Olu-Owolabi, B.; Yang, L.; Kong, L. Adsorption of Pb (II) and Cd (II) from aqueous solutions onto sodium tetraborate-modified Kaolinite clay: Equilibrium and thermodynamic studies. Hydrometallurgy 2008, 93, 1-9. [CrossRef]

2. Fei, W.; Wang, L.J.; Li, J.S.; Sun, X.Y.; Han, W.Q. Adsorption behavior and mechanism of cadmium on strong-acid cation exchange resin. Trans. Nonferrous Met. Soc. China 2009, 19, 740-744.

3. Khan, M.A.; Khan, S.; Khan, A.; Alam, M. Soil contamination with cadmium, consequences and remediation using organic amendments. Sci. Total Environ. 2017, 601-602, 1591-1605. [CrossRef]

4. Li, P.; Wang, X.; Allinson, G.; Li, X.; Xiong, X. Risk assessment of heavy metals in soil previously irrigated with industrial wastewater in Shenyang, China. J. Hazard. Mater. 2009, 161, 516-521. [CrossRef] [PubMed] 
5. Ma, L.; Xu, R.; Jiang, J. Adsorption and desorption of $\mathrm{Cu}(\mathrm{II})$ and $\mathrm{Pb}(\mathrm{II})$ in paddy soils cultivated for various years in the subtropical China. J. Environ. Sci. 2010, 22, 689-695. [CrossRef]

6. Lee, C.S.L.; Li, X.; Shi, W.; Cheung, S.C.N.; Thornton, I. Metal contamination in urban, suburban, and country park soils of Hong Kong: A study based on GIS and multivariate statistics. Sci. Total Environ. 2006, 356, 45-61. [CrossRef] [PubMed]

7. Li, Z.; Ma, Z.; van der Kuijp, T.J.; Yuan, Z.; Huang, L. A review of soil heavy metal pollution from mines in China: Pollution and health risk assessment. Sci. Total Environ. 2014, 468-469, 843-853. [CrossRef]

8. Luo, X.L.; Guo, Q.R.; Xie, Z.Y.; Yang, J.J.; Chai, Z.W.; Liu, X.; Wu, S.F. Study on heavy metal pollution in typical rural soils in Pearl River Delta area. Ecol. Environ. Sci. 2014, 23, 485-489.

9. Mohapatra, M.; Anand, S. Studies on sorption of Cd(II) on Tata chromite mine overburden. J. Hazard. Mater. 2007, 148, 553-559. [CrossRef]

10. Xinxin, Y.; Yibing, M.; Bo, S. Influence of soil type and genotype on Cd bioavailability and uptake by rice and implications for food safety. J. Environ. Sci. 2012, 24, 1647-1654.

11. Wu, S.; Zhang, K.; Wang, X.; Jia, Y.; Sun, B.; Luo, T.; Meng, F.; Jin, Z.; Lin, D.; Shen, W.; et al. Enhanced adsorption of cadmium ions by 3D sulfonated reduced graphene oxide. Chem. Eng. J. 2015, 262, 1292-1302. [CrossRef]

12. Huang, F.; Gao, L.-Y.; Deng, J.-H.; Chen, S.-H.; Cai, K.-Z. Quantitative contribution of Cd 2+ adsorption mechanisms by chicken-manure-derived biochars. Environ. Sci. Pollut. Res. 2018, 25, 28322-28334. [CrossRef]

13. Zhao, Z.; Nie, T.; Yang, Z.; Zhou, W. The role of soil components in the sorption of tetracycline and heavy metals in soils. RSC Adv. 2018, 8, 32178-32187. [CrossRef]

14. Srivastava, P.; Singh, B.; Angove, M. Competitive adsorption behavior of heavy metals on kaolinite. J. Colloid Interface Sci. 2005, 290, 28-38. [CrossRef] [PubMed]

15. Mustafa, G.; Kookana, R.S.; Singh, B. Desorption of cadmium from goethite: Effects of pH, temperature and aging. Chemosphere 2006, 64, 856-865. [CrossRef]

16. Gerritse, R.G.; Van Driel, W. The Relationship Between Adsorption of Trace Metals, Organic Matter, and pH in Temperate Soils. J. Environ. Qual. 1984, 13, 197-204. [CrossRef]

17. Glover, L.J., II; Eick, M.J.; Brady, P.V. Desorption Kinetics of Cadmium2 and Lead2 from Goethite: Influence of Time and Organic Acids. Soil Sci. Soc. Am. J. 2002, 66, 797-804. [CrossRef]

18. Shirvani, M.; Shariatmadari, H.; Kalbasi, M. Kinetics of cadmium desorption from fibrous silicate clay minerals: Influence of organic ligands and aging. Appl. Clay Sci. 2007, 37, 175-184. [CrossRef]

19. Elliott, H.A.; Liberati, M.R.; Huang, C.P. Effect of iron oxide removal on heavy metal sorption by acid subsoils. Water Air Soil Pollut. 1986, 27, 379-389. [CrossRef]

20. Singh, B.; Alloway, B.J.; Bochereau, F.J.M. Cadmium sorption behavior of natural and synthetic zeolites. Commun. Soil Sci. Plant Anal. 2000, 31, 2775-2786. [CrossRef]

21. Jobstmann, H.; Singh, B. Cadmium Sorption by Hydroxy-Aluminium Interlayered Montmorillonite. Water Air Soil Pollut. 2001, 131, 203-215. [CrossRef]

22. Spark, K.; Wells, J.; Johnson, B. Characterizing trace metal adsorption on kaolinite. Eur. J. Soil Sci. 1995, 46, 633-640. [CrossRef]

23. Alaboudi, K.A.; Ahmed, B.; Brodie, G. Phytoremediation of $\mathrm{Pb}$ and $\mathrm{Cd}$ contaminated soils by using sunflower (Helianthus annuus) plant. Ann. Agric. Sci. 2018, 63, 123-127. [CrossRef]

24. Wang, J.; Lv, J.; Fu, Y. Effects of organic acids on Cd adsorption and desorption by two anthropic soils. Front. Environ. Sci. Eng. 2012, 7, 19-30. [CrossRef]

25. Pardo, M. Sorption of lead, copper, zinc, and cadmium by soils: Effect of nitriloacetic acid on metal retention. Commun. Soil Sci. Plant. Anal. 2000, 31, 31-40. [CrossRef]

26. Sparks, D.L. Environmental Soil Chemistry, 2nd ed.; Elsevier: Amsterdam, The Netherlands, 2003.

27. Wang, Y.; Tang, X.; Chen, Y.; Zhan, L.; Li, Z.; Tang, Q. Adsorption behavior and mechanism of Cd(II) on loess soil from China. J. Hazard. Mater. 2009, 172, 30-37. [CrossRef] [PubMed]

28. Tran, Y.; Barry, D.; Bajracharya, K. Cadmium desorption in sand. Environ. Int. 2002, 28, 493-502. [CrossRef]

29. Zhang, D.L.; Jin, M.G.; Fang, Y.; Zhou, X.; Mei, Y.U. Effect of different acidic conditions on the adsorption-desorption characteristics of Cd (2+) in a silt loam. Soil Fertil. Sci. China 2014, 04, 29-34.

30. Lu, R.K. Methods for Soil Agrochemistry Analysis; China Agricultural Science and Technology Press: Beijing, China, 2000.

31. Klute, A. Physical and mineralogical methods; American Society of Agronomy: Madison, WI, USA, 1986.

32. Pansu, M.; Gautheyrou, J. Handbook of Soil Analysis; Springer: Berlin/Heidelberg, Germany, 2006.

33. Amacher, M.; Spark, D. Nickel, cadmium and lead. Methods Soil Anal. Part. Chem. Methods 1996, 5, 739-768.

34. Nordberg, G.F.; Fowler, B.A.; Nordberg, M. (Eds.) Handbook on the Toxicology of Metals; Elsevier B.V.: Amestardam, The Netherlands, 2015.

35. Fan, H.-T.; Sun, Y.; Tang, Q.; Li, W.-L.; Sun, T. Selective adsorption of antimony(III) from aqueous solution by ion-imprinted organic-inorganic hybrid sorbent: Kinetics, isotherms and thermodynamics. J. Taiwan Inst. Chem. Eng. 2014, 45, 2640-2648. [CrossRef]

36. Zhou, Y.; Liu, X.; Xiang, Y.; Wang, P.; Zhang, J.; Zhang, F.; Wei, J.; Luo, L.; Lei, M.; Tang, L. Modification of biochar derived from sawdust and its application in removal of tetracycline and copper from aqueous solution: Adsorption mechanism and modelling. Bioresour. Technol. 2017, 245, 266-273. [CrossRef] 
37. Foo, K.Y.; Hameed, B.H. Insights into the modeling of adsorption isotherm systems. Chem. Eng. J. 2010, 156, 2-10. [CrossRef]

38. Huang, B.; Li, Z.; Huang, J.; Guo, L.; Nie, X.; Wang, Y.; Zhang, Y.; Zeng, G. Adsorption characteristics of Cu and Zn onto various size fractions of aggregates from red paddy soil. J. Hazard. Mater. 2014, 264, 176-183. [CrossRef]

39. Ahmed, I.; Helal, A.A.; El Aziz, N.A.; Gamal, R.; Shaker, N.O. Influence of some organic ligands on the adsorption of lead by agricultural soil. Arab. J. Chem. 2019, 12, 2540-2547. [CrossRef]

40. Gao, R.; Xiang, L.; Hu, H.; Fu, Q.; Zhu, J.; Liu, Y.; Huang, G. High-efficiency removal capacities and quantitative sorption mechanisms of $\mathrm{Pb}$ by oxidized rape straw biochars. Sci. Total Environ. 2020, 699, 134262. [CrossRef]

41. Gupta, S.S.; Bhattacharyya, K.G. Kinetics of adsorption of metal ions on inorganic materials: A review. Adv. Colloid Interface Sci. 2011, 162, 39-58. [CrossRef]

42. Zhu, L.; Tong, L.; Zhao, N.; Wang, X.; Yang, X.; Lv, Y. Key factors and microscopic mechanisms controlling adsorption of cadmium by surface oxidized and aminated biochars. J. Hazard. Mater. 2020, 382, 121002. [CrossRef]

43. Rashti, M.R.; Esfandbod, M.; Adhami, E.; Srivastava, P. Cadmium desorption behaviour in selected sub-tropical soils: Effects of soil properties. J. Geochem. Explor. 2014, 144, 230-236. [CrossRef]

44. Komy, Z.R.; Shaker, A.M.; Heggy, S.E.; El-Sayed, M.E. Kinetic study for copper adsorption onto soil minerals in the absence and presence of humic acid. Chemosphere 2014, 99, 117-124. [CrossRef] [PubMed]

45. Guo, Y.; Tang, W.; Wu, J.; Huang, Z.; Dai, J. Mechanism of $\mathrm{Cu}(\mathrm{II})$ adsorption inhibition on biochar by its aging process. J. Environ. Sci. 2014, 26, 2123-2130. [CrossRef] [PubMed]

46. Naidu, R.; Kookana, R.S.; Sumner, M.E.; Harter, R.D.; Tiller, K.G. Cadmium Sorption and Transport in Variable Charge Soils: A Review. J. Environ. Qual. 1997, 26, 602-617. [CrossRef]

47. Choi, Y.-K.; Choi, T.-R.; Gurav, R.; Bhatia, S.K.; Park, Y.-L.; Kim, H.J.; Kan, E.; Yang, Y.-H. Adsorption behavior of tetracycline onto Spirulina sp. (microalgae)-derived biochars produced at different temperatures. Sci. Total Environ. 2020, 710, 136282. [CrossRef]

48. Feng, Q.; Zhang, Z.; Chen, Y.; Liu, L.; Zhang, Z.; Chen, C. Adsorption and Desorption Characteristics of Arsenic on Soils: Kinetics, Equilibrium, and Effect of $\mathrm{Fe}(\mathrm{OH}) 3$ Colloid, H2SiO3 Colloid and Phosphate. Procedia Environ. Sci. 2013, 18, 602-617. [CrossRef]

49. Zhou, J.; Ma, F.; Guo, H. Adsorption behavior of tetracycline from aqueous solution on ferroferric oxide nanoparticles assisted powdered activated carbon. Chem. Eng. J. 2020, 384, 123290. [CrossRef]

50. Zhao, X.; Jiang, T.; Du, B. Effect of organic matter and calcium carbonate on behaviors of cadmium adsorption-desorption on/from purple paddy soils. Chemosphere 2014, 99, 41-48. [CrossRef] [PubMed]

51. Borggaard, O.K.; Holm, P.E.; Strobel, B.W. Potential of dissolved organic matter (DOM) to extract $\mathrm{As}, \mathrm{Cd}, \mathrm{Co}, \mathrm{Cr}, \mathrm{Cu}, \mathrm{Ni}, \mathrm{Pb}$ and Zn from polluted soils: A review. Geoderma 2019, 343, 235-246. [CrossRef]

52. Xu, R.; Xiao, S.; Zhao, A.; Ji, G. Effect of $\mathrm{Cr}(\mathrm{VI})$ anions on adsorption and desorption behavior of $\mathrm{Cu}(\mathrm{II})$ in the colloidal systems of two authentic variable charge soils. J. Colloid Interface Sci. 2005, 284, 22-29. [CrossRef]

53. Khan, M.A.; Khan, S.; Ding, X.; Khan, A.; Alam, M. The effects of biochar and rice husk on adsorption and desorption of cadmium on to soils with different water conditions (upland and saturated). Chemosphere 2018, 193, 1120-1126. [CrossRef] [PubMed]

54. Guo, X.; Zhang, S.; Shan, X.-Q.; Luo, E.I.L.; Pei, Z.; Zhu, Y.-G.; Liu, T.; Xie, Y.-N.; Gault, A. Characterization of Pb, Cu, and Cd adsorption on particulate organic matter in soil. Environ. Toxicol. Chem. 2006, 25, 2366-2373. [CrossRef] 